\title{
Bridging infectious disease vaccines with cancer immunotherapy: a role for targeted RNA based immunotherapeutics
}

\author{
Elias J Sayour ${ }^{1,2}$, Luis Sanchez-Perez ${ }^{3}$, Catherine Flores ${ }^{1}$ and Duane A Mitchell ${ }^{1 *}$
}

\begin{abstract}
Tumor-specific immunotherapy holds the promise of eradicating malignant tumors with exquisite precision without additional toxicity to standard treatments. Cancer immunotherapy has conventionally relied on cell-mediated immunity while successful infectious disease vaccines have been shown to induce humoral immunity. Efficacious cancer immunotherapeutics likely require both cellular and humoral responses, and RNA based cancer vaccines are especially suited to stimulate both arms of the immune system. RNA is inherently immunogenic, inducing innate immune responses to initiate cellular and humoral adaptive immunity, but has limited utility based on its poor in vivo stability. Early work utilized 'naked' RNA vaccines, whereas more recent efforts have attempted to encapsulate RNA thereby protecting it from degradation. However, feasibility has been limited by a lack of defined and safe targeting mechanisms for the in vivo delivery of stabilized RNA. As new cancer antigens come to the forefront with novel RNA encapsulation and targeting techniques, RNA vaccines may prove to be a vital, safe and robust method to initiate patient-specific anti-tumor efficacy.
\end{abstract}

Keywords: RNA, Vaccines, Immunotherapy

\section{Introduction}

Tumor-specific immunotherapy is a burgeoning field targeting tumor antigens in the form of peptides, nucleic acids, and cell lysates to induce host-immunity [1]. The exquisite specificity of the immune system and the recent demonstrated efficacy of immune-based treatment of advanced cancers upholds immunotherapy as a promising therapeutic modality; however, the immune correlates necessary to guide successful intervention remain elusive [2-7]. While further testing is necessary, both humoral and cell-mediated immunity are likely paramount for successful cancer immunotherapeutics [4,8-11]. To bypass the complexity of cellular therapeutics, cancer vaccinations have been advanced to recruit adaptive responses, but have suffered from their weak immunogenicity in human clinical trials [11]. This has prompted the development of RNA cancer vaccines designed to mimic infectious

\footnotetext{
* Correspondence: duane.mitchell@neurosurgery.ufl.edu

'Department of Neurosurgery, UF Brain Tumor Immunotherapy Program, University of Florida, Gainesville, Fl, USA

Full list of author information is available at the end of the article
}

challenge, thereby stimulating the innate immune system to augment cellular and humoral immunity [12].

Although some infectious disease vaccines are capable of inducing cell-mediated immunity, humoral immune responses remain the hallmark of effective infectious disease vaccination strategy [13]. These vaccination strategies can be broken down into anti-bacterial immunizations using inactivated prokaryotic proteins, capsular or conjugated polysaccharides, and anti-viral immunizations utilizing inactivated killed virions or live attenuated viral vaccines [14]. A better understanding of infectious vaccine approaches and immunological responses may bolster current RNA cancer immunotherapeutic strategies.

\section{Review}

Efficacious infectious disease vaccines

Bacterial immunizations for diphtheria, tetanus, pertussis, (collectively known as DTaP- diphtheria-tetanus-acellular pertussis vaccine), all utilize aluminum (alum) containing adjuvants, and demonstrated efficacious and prophylactic immune responses prompting their adoption into the primary vaccination series in children [15]. Inactivated 
protein antigens from these bacteria are injected with alum salts, initiating inflammation that recruits dendritic cells (DCs) to process bacterial antigens for MHC class II presentation to $\mathrm{CD}_{4}^{+} \mathrm{T}$ lymphocytes initiating Th2 responses that induce humoral immunity [15-18]. Additionally, polysaccharide antigens have been utilized to induce humoral responses; these include the 23 valent capsular polysaccharide vaccine against pneumococcus (Pneumovax), and the 4 valent polysaccharide vaccine against meningiococcus (MPSV-4) [9]. Since polysaccharide vaccines primarily induce a B-cell-dependent immune response, preventing bacteremia but not fully protecting against pneumococcal or meningococcal infections, conjugation of capsular polysaccharides with a highly immunogenic protein, (i.e. a non-toxic diphtheria toxoid), has been shown to induce B- and T-cell helper responses for more complete protection [19]. This has been employed in the development of conjugated polysaccharide vaccines including Prevnar-13 for pneumococcus, and MCV-4 (Menactra) for meningiococcus [9].

Similar to inactivated bacterial vaccines, viral vaccines induce humoral immunity through a Th2 dependent response; however there is growing evidence that Th1 mediated immunity plays a prominent role in the induction of antigen specific CD8+ $\mathrm{T}$ cells after administration of live RNA viral vaccines [19-30]. For example, influenza $A$ is an RNA virus that can be prepared as both a live attenuated, or killed whole-virion vaccine [31,32]. Unlike killed influenza viruses which contain the inactive viral glycoprotein (hemagglutinin) for the induction of humoral immunity, the attenuated influenza virus contains a live single stranded RNA genome [31,32]. This RNA-genome activates plasmacytoid DCs (pDCs) through TLRs inducing type I IFN production, while activating conventional DCs and stromal cells through retinoic acid-inducible gene I (RIG-I) dependent sensors thereby eliciting potent Th1 $\mathrm{T}$ cell immunity [31-37]. Additional examples include the yellow fever RNA whole viral vaccine (YF-17D), which activates DCs through concomitant TLR and RIG I activation, inducing prominent type I interferon (IFN) and $\mathrm{CD}^{+} \mathrm{T}$ cell responses [22-24]. Similarly, the DNA vaccinia virus for smallpox may stimulate several pathogen recognition receptors (PRRs) eliciting the induction of $\mathrm{CD} 8^{+} \mathrm{T}$ cell expansion, IFN production, and memory formation [24-26,28,30]. Longitudinal analyses of $\mathrm{T}$ cell responses responding to the live yellow fever virus and smallpox vaccines demonstrated brisk and specific primary effector $\mathrm{CD} 8+\mathrm{T}$ cell responses that ultimately differentiated into long-lived highly functional memory cells [38]. Despite these observations, Bacille CalmetteGuérin (BCG), a live attenuated strain closely related to Mycobacterium tuberculosis, is one of the only licensed vaccines thought to work primarily through Th1 T-cell responses $[29,39]$. The immunogenicity of BCG is attributed to TLR recognition of the bacterial cell wall and nucleic acid-sensing PRRs; however, $\mathrm{CD}^{+}{ }^{+} \mathrm{T}$-cell responses are highly variable rendering the efficacy of BCG vaccines unreliable in a clinical setting [40-42].

Thus, while infectious vaccine strategies have had tremendous success, notwithstanding BCG, they have historically relied on humoral immune responses. RNA viruses administered as whole viral vaccines, evidenced by attenuated influenza and yellow fever conjugates, can induce combinatorial Th1 and Th2 responses suggesting that a synergistic approach between cellular and humoral immunity may mediate efficacy in malignancies and resistant infectious diseases.

\section{Cancer immunotherapeutic RNA vaccines}

RNA is recognizable by pathogen-associated molecular patterns (PAMPs), which are potent stimulators of PRRs such as TLR receptors $7 / 8$ thereby activating DCs to initiate anti-tumor responses [43-46]. The activation of these antigen presenting cells (APCs) induces Th1 and Th2 type responses through type I IFN signaling via PAMP recognition by PRRs [12].

\section{Nucleic acid vaccines}

Based on their propensity for inducing both antibody and $\mathrm{T}$ cell responses, nucleic acids encoding for cancer antigens are an attractive immunotherapeutic platform for the transfection of APCs [47]. The magnitude of these responses has been lower in DNA vaccines, which are hampered by inadequate delivery mechanisms and mired with constraints of crossing both cell and nuclear membranes $[20,47]$. The etiology for DNA's poor immunogenicity remains unclear, but may involve lower expression of DNA-sensing machinery, differing expression patterns of nucleic acid-sensing PRRs or issues related to DNA delivery and processing in different cell types [47-49]. These concerns, along with the potential for oncogenesis through genomic integration, have ignited RNA vaccine research as a promising alternative [47]. RNA vaccines are advantageous since they require only cytoplasm for entry, cannot be integrated into the genome, and are easy to produce and store [50]. RNA can be derived from limited tumor specimens, amplified to generate copious amounts of patient-specific tumor antigens, and be delivered to patients using ex vivo priming of autologous DCs or in vivo delivery to target APCs [51-53].

\section{'Naked' RNA cancer vaccines}

The initial experiments with RNA vaccines demonstrated that direct injection of messenger RNA (mRNA) into murine skeletal muscle induced in vivo gene expression [54]. These initial observations provided the foundation for later experiments exploring the anti-tumor immunity elicited from mRNA expression of cancer antigens [55]. One of the first mRNA polynucleotide vaccines was 
constructed using mRNA transcripts encoding for the human carcinoembryonic antigen (CEA), which conferred protective immunity in mice challenged with CEA-expressing tumor cells [55]. RNA transcripts in these experiments were stabilized through $5^{\prime}$ end capping, $3^{\prime}$ end polyadenylation and through incorporation of the human beta-globin $5^{\prime}$ and $3^{\prime}$ untranslated regions (UTRs) [55]. Direct injection of naked mRNA stabilized with betaglobin UTRs has been shown to prime Th2 responses that can be shifted to Th1 responses after administration of GM-CSF in mice [56]. Given the short in vivo half-life of RNA from local and systemic administration, other studies have focused on direct injection of RNA into target organs [57-59]. Direct injection of human alpha-1 antitrypsin mRNA into mouse epidermis using gene gun treatment elicited potent antibody responses with increasing titers after subsequent vaccinations [57]. Additionally, gene gun-based immunization using RNA coding for the melanocytic self-antigen TRP2 linked to EGFP demonstrated effective induction of anti-tumor immunity in a murine melanoma model [58]. Other methods of direct injection have included intranodal injection of RNA directly into secondary lymphoid organs inducing anti-tumor immunity in a murine melanoma model [59]. Interestingly, systemic administration of FLT3 ligand prior to intranodal injection of RNA dramatically enhanced priming and expansion of antigen-specific CD8(+) $\mathrm{T}$ cells in lymphoid organs, T-cell homing to melanomas, and anti-tumor efficacy $[59,60]$.

Much of this pre-clinical data has led to the translation of naked RNA vaccination into phase I trials for refractory malignancies $[61,62]$. In a phase I/II trial, total tumorderived RNA from melanomas, administered intradermally in conjunction with GM-CSF, was safe, but of uncertain efficacy [61]. These patients were vaccinated with autologous amplified tumor mRNA that could be produced in unlimited amounts from a personalized cRNA library representing a tumor specific transcriptome [63]. In a phase I/II trial for patients with renal cell carcinoma (RCC), naked RNA encoding for tumor-associated RCC antigens was co-administered with GM-CSF and was shown to precipitate anti-tumor immunity [62]. These vaccines generated $\mathrm{CD} 8+$ and $\mathrm{CD} 4+$ immune responses with no severe side effects and induced fifteen stable disease responses out of thirty evaluable patients with RCC [62].

Alternatively, strategies have focused on making 'naked' RNA vaccines self-replicating [64-66]. In these strategies, viral structural genes are replaced by mRNAs encoding for cancer antigens, which can be synthesized and replicated by the virus' non-structural machinery [64,66-69]. Immunizations with a self-replicating RNA immunogen derived from the Semliki forest virus, elicited antigen-specific antibody and CD8+ T-cell responses against model antigens and prolonged the survival of mice with established tumors [64]. In a human phase I trial against colorectal cancer metastases, tumor RNA packaged into alphaviral vectors were capable of efficiently infecting DCs and induced clinically relevant $\mathrm{T}$ cell and antibody responses [70]. Despite these attempts, viral engineering of RNA vaccines requires targeted approaches, and contains safety and feasibility issues such as bypassing the induction of vector-specific neutralizing antibodies [70].

Other methods have focused on condensing 'naked' RNA to enhance its stability and immunogenicity. RNA can be stabilized through incorporation of polypeptide cations such as protamines which function to condense nucleic acid [46]. These mRNA-protamine complexes have been shown to be a potent immune stimulus activating murine cells through a MyD88, TLR7 dependent pathway and induced anti-tumor immunity in a murine glioma model after direct intratumoral injection [46,71-73]. They have also been shown to provide balanced cell mediated and humoral immunity when codelivered with naked uncomplexed mRNA [44,74]. In a phase I/II trial for patients with metastatic melanoma, intradermal injection of protamine-stabilized mRNAs coding for melanoma antigens was shown to be safe and feasible with one complete remission [75]. Additionally, the use of protamine condensed RNA has allowed for the development of novel self-adjuvanted vaccines containing nucleotide modifications to mRNA transcripts [44,72]. Whereas protein and peptide-based tumor vaccines require strong adjuvants to induce immunity, non-coding long chain RNA-based adjuvants were shown to induce enhanced immunostimulatory effects over poly(I:C) and may further enhance the immunogenicity of selfadjuvanted mRNA cancer vaccines [76]. Currently, self-adjuvanted mRNA cancer vaccines encoding for commonly expressed tumor associated antigens are in clinical trials for patients with stage IV non-small cell lung cancer (NSCLC) and prostate cancer $[77,78]$.

\section{RNA encapsulated vaccines}

While the initial attempts using naked RNA have been promising, RNA degradation remains a concern limiting the amount of RNA available for cellular internalization [56]. To protect and deliver RNA to target cells, the delivery mechanism must be safe, feasible, clinically translatable, and amenable to 'off the shelf' manufacturing and distribution for the population at large. Based on these criteria, liposomes have been studied as vehicles for RNA vaccines and have been shown to induce antigen-specific cytotoxic $\mathrm{T}$ lymphocytes in vivo [79]. Since liposomes deliver their contents intracellularly via receptor-mediated endocytosis, the contents of the endosome are frequently shunted into lysosomal degradation pathways prompting the 
development of $\mathrm{pH}$ sensitive liposomes triggering antigen release for $\mathrm{MHC}$ processing at low $\mathrm{pH}$ levels [80]. These specialized liposomes have been shown to load DCs in vitro with mRNA coding for tumor associated antigens, elict cytotoxic $\mathrm{T}$ cell responses in murine models, and induce suppression of metastatic spread in a murine melanoma model [81-84]. Liposomes can be combined with polymers to form lipopolyplexes and have been formulated with a polyethylene glycol (PEG)ylated derivative of histidylated polylysine to encapsulate MART1 antigens inducing protective anti-tumor immunity in a murine melanoma model $[66,85]$. They can also be combined with self-amplifying RNA or protamine condensed RNA $[65,86]$. Self-amplifying RNA liposomes were shown to elicit antigen-specific interferon- $\gamma$-producing CD4+ and CD8+ T-cells in a murine model for respiratory syncytial infection [65]. Similarly, protamine condensed RNA liposomes coding for the model antigen beta-galactosidase induced cytotoxic $\mathrm{T}$ cell and antibody mediated immunity in an in vivo model $[65,86]$. In addition to encapsulating novel RNA designs, liposomes can be combined with viral envelopes forming virosomes (liposomes containing viral envelopes) for the encapsulation and delivery of tumor antigens [87]. Fusion-active virosomes have been shown to deliver protein encapsulated ovalbumin (OVA) to DCs for MHC class I presentation at picomolar OVA concentrations [87]. Although liposomes have an attractive safety profile, many of the these approaches remain limited by decreased targeting efficiency, and reticular endothelial elimination thereby mitigating the potency of the immune response [80].

\section{Targeting RNA vaccines}

Future vaccine strategies will build on the success of previous advances while ameliorating the limitations of the immunogenic but highly degradable naked RNA vaccines, and the limitations of the protected but inefficient delivery of RNA-liposomal vaccines. The safety and stability profile of liposomes is attractive, and the immunogenicity of RNA is appealing for initiating prolific immune responses. Since RNA-liposomes cannot hone to targeted cells, engineering targeting ligands and moieties may be utilized to transfect desired cells. Pre-clinical studies have shown that IgG-coated liposomes are efficiently taken up and presented to $\mathrm{T}$ cells by dendritic cells via Ig FcR while mannosylated liposomes enhance uptake and activation of DCs $[88,89]$. Meanwhile, single chain antibody fragments (scFv) have been developed against DC receptors CD11c or DEC-205 attached to liposome surfaces, demonstrating efficient DC targeting and anti-tumor immunity [90]. Alternatively, DCs can be ex vivo transfected with RNA through liposomal transfection or electroporation before in vivo re-introduction [91,92]. These RNA loaded DCs have been shown to stimulate polyclonal $\mathrm{T}$ cell responses against antigens expressed in RCC and metastatic colon cancer $[53,93,94]$. In a phase I trial for metastatic prostate tumors, autologous dendritic cells transfected with prostate-specific antigen RNA stimulated PSA specific cytotoxic T lymphocyte responses [21]. Similarly, in a phase IB study in pretreated advanced melanoma patients, vaccination with monocyte-derived DCs, electroporated with mRNA coding for melanoma-associated antigen combined with immunostimulatory RNAs (isRNAs) (i.e. CD40 ligand, TLR 4 and CD70), induced tumor associated antigen (TAA) CD8+ immunity $[95,96]$. In these pretreated advanced melanoma patients, two of fifteen patients achieved a complete response and two achieved partial response [95]. While these findings are encouraging, the advancement of ex vivo generated cellular vaccines through multi-institutional clinical trials and eventual distribution for widespread clinical utility has proven to be fraught with developmental challenges prompting others to prioritize the advancement of RNA-loaded nanoparticle vaccines as an attractive, "off-the-shelf" targeted therapeutic platform.

\section{RNA-loaded nanoparticles}

Nanomaterials have been utilized to deliver drugs directly to malignant tissues, bypassing their systemic toxicity [97]. Given the unique physical properties of nanoparticles (NPs) (i.e. size, charge, biocompatibility, solubility), they can be manipulated to increase circulation half-life, accumulation, and drug cargo inside tumors [97]. Nanoscale drug payloads can be associated with targeting ligands and encapsulation techniques to prevent degradation and can be further designed into multi-functional delivery systems with tumor-specific targeting moieties, therapeutic payloads, and diagnostic tools [97-101]. In cancer therapy, NPs have a multitude of various advantages including bypassing multi-drug resistance mechanisms, accessing solid tumors, and engineering the tumor microenvironment [97]. Several pre-clinical studies have investigated the immunogenicity of novel RNA-NP designs. Lipid-like materials, termed "lipidoids," were shown to deliver immunostimulatory RNA (isRNA) to TLR-expressing cells inducing potent anti-ovalbumin humoral and cell-mediated responses [102]. Similarly, pluronic-stabilized polypropylene sulfide nanoparticles were developed to target antigens in the lung and were shown to deliver their contents to pulmonary DCs inducing potent protective mucosal and systemic $\mathrm{CD} 8(+)$ T-cell immunity in murine models [103]. Other examples of targeted RNA-nanoparticle immunotherapeutics include mannosylated and histidylated lipopolyplexes loaded with mRNA; these nanoparticles were shown to enhance in vivo DC transfection and anti-tumor immunity against a murine melanoma model [104]. 
Despite this active area of research, the arrival of approved nano-drugs to the market has been slow with only a handful of FDA-approved agents [97,105]. Before nanomaterials can be used in cancer treatments, biodistribution and toxicity must be addressed which depend on the NP size, shape, deformability and surface chemistry (i.e. charge, and $\mathrm{pH}$ ), all of which are poorly understood in a complex in vivo system containing plasma proteins that may alter a nanomaterial's surface property and affect its biocompatibility [106]. These challenges make each particle, and its toxicity, unique and difficult to investigate as each falls under a diffuse realm of categories including drugs, devices, and biological agents [106-109]. Based on these inherent complications, FDA approval of NPs has stagnated, and most approved agents have only been used in the context of drug delivery where toxicity has traditionally been secondary to the drug as opposed to the biocompatible nanomaterial $[109,110]$.

\section{Conclusion}

Cancer vaccines can meet the challenge of targeted cancer care, but require strong adjuvants to re-direct a 'tolerant' immune system. We can look to infectious disease vaccines as a model for successful immunization strategies. While most infectious disease vaccines function through induction of humoral immunity, RNA viral vaccines such as influenza and yellow fever have been shown to generate robust cellular and humoral immunity. To leverage successful cancer immunotherapeutic RNA vaccination strategies, traditional methods in conjunction with novel adaptations are requisite in developing safe and effective formulations that protect RNA from degradation, deliver payload to target, and remain amenable to central manufacturing and distribution. The rapid advancements being made in in vivo targeting technologies, particularly in the area of nanomaterials engineering, and our understanding of the requirements for successful induction of potent anti-tumor immunity promise to yield the development of effective and safe RNA vaccines for the treatment of refractory cancers.

\footnotetext{
Abbreviations

APC: Antigen presenting cell: APC; Alum: Aluminum; BCG: Bacille Calmette-Guérin; CEA: Carcinoembryonic antigen; DCs: Dendritic cells; HiB: Haemophilus influenzae type b; isRNA: Immunostimulatory RNA; IFN: Interferon; mRNA: Messenger RNA; NSCLC: Non-squamous cell lung carcinoma; OVA: Ovalbumin; PAMP: Pathogen associated molecular pattern; PRRS: Pathogen recognition receptors; pDCs: Plasmacytoid DCs; PEG: Polyethylene glycol; RCC: Renal Cell Carcinoma; RIG-I: Retinoic acid-inducible gene I; TAA: Tumor associated antigen; UTR: Untranslated Regions.
}

\section{Competing interests}

The authors declare that they have no competing interests.

\section{Authors' contributions}

EJS and DAM conceived of and wrote the review. LSP and CF helped write the review. All authors read and approved the final manuscript.

\section{Acknowledgement}

This work was supported by the Preston A. Wells, Jr. Center for Brain Tumor Therapy Research Fund and the American Brain Tumor Association.

\section{Author details}

'Department of Neurosurgery, UF Brain Tumor Immunotherapy Program, University of Florida, Gainesville, Fl, USA. ${ }^{2}$ Department of Pathology, Duke University Medical Center, Durham, NC, USA. ${ }^{3}$ Division of Neurosurgery, Department of Surgery, Duke Brain Tumor Immunotherapy Program, Duke University Medical Center, Durham, NC, USA.

Received: 17 November 2014 Accepted: 18 March 2015

Published online: 21 April 2015

\section{References}

1. Mitchell DA, Nair SK. RNA transfected dendritic cells as cancer vaccines. Curr Opin Mol Ther. 2000;2:176-81.

2. Kantoff PW, Higano CS, Shore ND, Berger ER, Small EJ, Penson DF, et al. Sipuleucel-T immunotherapy for castration-resistant prostate cancer. N Engl J Med. 2010;363:411-22.

3. Hodi FS, O'Day SJ, McDermott DF, Weber RW, Sosman JA, Haanen JB, et al. Improved survival with ipilimumab in patients with metastatic melanoma. N Engl J Med. 2010;363:711-23.

4. Babu R, Adamson DC. Rindopepimut: an evidence-based review of its therapeutic potential in the treatment of EGFRvlll-positive glioblastoma. Core Evid. 2012;7:93-103.

5. Lee ST, Jiang YF, Park KU, Woo AF, Neelapu SS. BiovaxID: a personalized therapeutic cancer vaccine for non-Hodgkin's lymphoma. Expert Opin Biol Ther. 2007;7:113-22.

6. Sheikh NA, Petrylak D, Kantoff PW, Dela Rosa C, Stewart FP, Kuan LY, et al. Sipuleucel-T immune parameters correlate with survival: an analysis of the randomized phase 3 clinical trials in men with castration-resistant prostate cancer. Cancer Immunol Immunother. 2013;62:137-47.

7. Yuan J, Adamow M, Ginsberg BA, Rasalan TS, Ritter E, Gallardo HF, et al. Integrated NY-ESO-1 antibody and CD8+ T-cell responses correlate with clinical benefit in advanced melanoma patients treated with ipilimumab. Proc Natl Acad Sci U S A. 2011;108:16723-8.

8. Sanchez-Perez L, Choi BD, Reap EA, Sayour EJ, Norberg P, Schmittling RJ, et al. BLyS levels correlate with vaccine-induced antibody titers in patients with glioblastoma lymphodepleted by therapeutic temozolomide. Cancer Immunol Immunother. 2013;62:983-7.

9. Xia J, Bolyard AA, Rodger E, Stein S, Aprikyan AA, Dale DC, et al. Prevalence of mutations in ELANE, GFI1, HAX1, SBDS, WAS and G6PC3 in patients with severe congenital neutropenia. Br J Haematol. 2009;147:535-42.

10. Restifo NP, Dudley ME, Rosenberg SA. Adoptive immunotherapy for cancer: harnessing the T cell response. Nat Rev Immunol. 2012;12:269-81.

11. Rosenberg SA. Raising the bar: the curative potential of human cancer immunotherapy. Sci Transl Med. 2012;4:127ps128.

12. Desmet CJ, Ishii KJ. Nucleic acid sensing at the interface between innate and adaptive immunity in vaccination. Nat Rev Immunol. 2012;12:479-91.

13. Bloch O, Crane CA, Kaur R, Safaee M, Rutkowski MJ, Parsa AT. Gliomas promote immunosuppression through induction of $\mathrm{B} 7-\mathrm{H} 1$ expression in tumor-associated macrophages. Clin Cancer Res. 2013;19:3165-75.

14. Kingwell K. Neuro-oncology: Glioblastoma prognosis linked to neuronal PD-L1 expression in tumour-adjacent tissue. Nat Rev Neurol. 2013; 9:602-3.

15. HogenEsch $\mathrm{H}$. Mechanisms of stimulation of the immune response by aluminum adjuvants. Vaccine. 2002;20 Suppl 3:S34-9.

16. Matzinger P. The danger model: a renewed sense of self. Science. 2002;296:301-5.

17. McKee AS, Munks MW, MacLeod MK, Fleenor CJ, Van Rooijen N, Kappler JW, et al. Alum induces innate immune responses through macrophage and mast cell sensors, but these sensors are not required for alum to act as an adjuvant for specific immunity. J Immunol. 2009;183:4403-14.

18. Marrack P, McKee AS, Munks MW. Towards an understanding of the adjuvant action of aluminium. Nat Rev Immunol. 2009;9:287-93.

19. Pletz MW, Maus U, Krug N, Welte T, Lode H. Pneumococcal vaccines: mechanism of action, impact on epidemiology and adaption of the species. Int J Antimicrob Agents. 2008;32:199-206.

20. Liu MA. Immunologic basis of vaccine vectors. Immunity. 2010;33:504-15. 
21. Germeshausen $M$, Deerberg $S$, Peter $Y$, Reimer $C$, Kratz $C P$, Ballmaier $M$. The spectrum of ELANE mutations and their implications in severe congenital and cyclic neutropenia. Hum Mutat. 2013;34:905-14.

22. Querec T, Bennouna S, Alkan S, Laouar Y, Gorden K, Flavell R, et al. Yellow fever vaccine YF-17D activates multiple dendritic cell subsets via TLR2, 7, 8, and 9 to stimulate polyvalent immunity. J Experiment Med. 2006;203:413-24.

23. Gaucher D, Therrien R, Kettaf N, Angermann BR, Boucher G, Filali-Mouhim A, et al. Yellow fever vaccine induces integrated multilineage and polyfunctional immune responses. J Experiment Med. 2008;205:3119-31.

24. Querec TD, Akondy RS, Lee EK, Cao W, Nakaya HI, Teuwen D, et al. Systems biology approach predicts immunogenicity of the yellow fever vaccine in humans. Nat Immunol. 2009:10:116-25.

25. Delaloye J, Roger T, Steiner-Tardivel QG, Le Roy D, Knaup Reymond M, Akira $\mathrm{S}$, et al. Innate immune sensing of modified vaccinia virus Ankara (MVA) is mediated by TLR2-TLR6, MDA-5 and the NALP3 inflammasome. PLoS Pathog. 2009;5:e1000480.

26. Zhu J, Martinez J, Huang $X$, Yang Y. Innate immunity against vaccinia virus is mediated by TLR2 and requires TLR-independent production of IFN-beta. Blood. 2007;109:619-25.

27. Quigley M, Martinez J, Huang X, Yang Y. A critical role for direct TLR2-MyD88 signaling in CD8 T-cell clonal expansion and memory formation following vaccinia viral infection. Blood. 2009:113:2256-64

28. Martinez J, Huang X, Yang Y. Toll-like receptor 8-mediated activation of murine plasmacytoid dendritic cells by vaccinia viral DNA. Proc Natl Acad Sci U S A. 2010;107:6442-7.

29. Thaiss CA, Kaufmann SH. Toward novel vaccines against tuberculosis: current hopes and obstacles. Yale J Biol Med. 2010;83:209-15.

30. Samuelsson C, Hausmann J, Lauterbach H, Schmidt M, Akira S, Wagner H, et al. Survival of lethal poxvirus infection in mice depends on TLR9, and therapeutic vaccination provides protection. J Clin Invest. 2008; 118:1776-84.

31. Diebold SS, Kaisho T, Hemmi H, Akira S, Reis e Sousa C. Innate antiviral responses by means of TLR7-mediated recognition of single-stranded RNA Science. 2004;303:1529-31.

32. Lund JM, Alexopoulou L, Sato A, Karow M, Adams NC, Gale NW, et al. Recognition of single-stranded RNA viruses by Toll-like receptor 7. Proc Natl Acad Sci U S A. 2004;101:5598-603.

33. Yoneyama M, Kikuchi M, Natsukawa T, Shinobu N, Imaizumi T, Miyagishi M, et al. The RNA helicase RIG-I has an essential function in double-stranded RNA-induced innate antiviral responses. Nat Immunol. 2004;5:730-7.

34. Kato H, Sato S, Yoneyama M, Yamamoto M, Uematsu S, Matsui K, et al. Cell type-specific involvement of RIG-I in antiviral response. Immunity. 2005;23:19-28.

35. Thomas PG, Dash P, Aldridge Jr JR, Ellebedy AH, Reynolds C, Funk AJ, et al. The intracellular sensor NLRP3 mediates key innate and healing responses to influenza A virus via the regulation of caspase-1. Immunity. 2009;30:566-75.

36. Koyama S, Aoshi T, Tanimoto T, Kumagai Y, Kobiyama K, Tougan T, et al. Plasmacytoid dendritic cells delineate immunogenicity of influenza vaccine subtypes. Sci Transl Med. 2010;2:25ra24.

37. Aoshi T, Koyama S, Kobiyama K, Akira S, Ishii KJ. Innate and adaptive immune responses to viral infection and vaccination. Curr Opin Virol. 2011;1:226-32.

38. Miller JD, van der Most RG, Akondy RS, Glidewell JT, Albott S, Masopust D, et al. Human effector and memory CD8+ T cell responses to smallpox and yellow fever vaccines. Immunity. 2008;28:710-22.

39. Ryan AA, Nambiar JK, Wozniak TM, Roediger B, Shklovskaya E, Britton WJ, et al. Antigen load governs the differential priming of CD8 T cells in response to the bacille Calmette Guerin vaccine or Mycobacterium tuberculosis infection. J Immunol. 2009;182:7172-7.

40. Mancuso G, Gambuzza M, Midiri A, Biondo C, Papasergi S, Akira S, et al. Bacterial recognition by TLR7 in the lysosomes of conventional dendritic cells. Nat Immunol. 2009;10:587-94.

41. von Meyenn F, Schaefer M, Weighardt H, Bauer S, Kirschning CJ, Wagner H, et al. Toll-like receptor 9 contributes to recognition of Mycobacterium bovis Bacillus Calmette-Guerin by Flt3-ligand generated dendritic cells. Immunobiology. 2006;211:557-65.

42. Colditz GA, Brewer TF, Berkey CS, Wilson ME, Burdick E, Fineberg HV, et al. Efficacy of BCG vaccine in the prevention of tuberculosis. Meta-analysis of the published literature. JAMA. 1994;271:698-702.

43. Nair SK, Heiser A, Boczkowski D, Majumdar A, Naoe M, Lebkowski JS, et al. Induction of cytotoxic $T$ cell responses and tumor immunity against unrelated tumors using telomerase reverse transcriptase RNA transfected dendritic cells. Nat Med. 2000;6:1011-7.

44. Fotin-Mleczek M, Duchardt KM, Lorenz C, Pfeiffer R, Ojkic-Zrna S, Probst J, et al. Messenger RNA-based vaccines with dual activity induce balanced TLR-7 dependent adaptive immune responses and provide antitumor activity. J Immunother. 2011;34:1-15.

45. Schlake T, Thess A, Fotin-Mleczek M, Kallen KJ. Developing mRNA-vaccine technologies. RNA Biol. 2012;9:1319-30.

46. Scheel B, Teufel R, Probst J, Carralot JP, Geginat J, Radsak M, et al. Toll-like receptor-dependent activation of several human blood cell types by protamine-condensed mRNA. Eur J Immunol. 2005;35:1557-66.

47. Ulmer JB, Mason PW, Geall A, Mandl CW. RNA-based vaccines. Vaccine 2012;30:4414-8

48. Coban C, Kobiyama K, Aoshi T, Takeshita F, Horii T, Akira S, et al. Novel strategies to improve DNA vaccine immunogenicity. Curr Gene Ther. 2011;11:479-84.

49. Guo C, Manjili MH, Subjeck JR, Sarkar D, Fisher PB, Wang XY. Therapeutic cancer vaccines: past, present, and future. Adv Cancer Res. 2013;119:421-75.

50. Kreiter S, Diken M, Selmi A, Tureci O, Sahin U. Tumor vaccination using messenger RNA: prospects of a future therapy. Curr Opin Immunol. 2011;23:399-406

51. Mitchell DA, Nair SK. RNA-transfected dendritic cells in cancer immunotherapy. J Clin Invest. 2000;106:1065-9.

52. Ancliff PJ, Gale RE, Liesner R, Hann IM, Linch DC. Mutations in the ELA2 gene encoding neutrophil elastase are present in most patients with sporadic severe congenital neutropenia but only in some patients with the familial form of the disease. Blood. 2001;98:2645-50.

53. Kasper B, Tidow N, Grothues D, Welte K. Differential expression and regulation of GTPases (RhoA and Rac2) and GDls (LyGDI and RhoGDI) in neutrophils from patients with severe congenital neutropenia. Blood. 2000;95:2947-53.

54. Wolff JA, Malone RW, Williams P, Chong W, Acsadi G, Jani A, et al. Direct gene transfer into mouse muscle in vivo. Science. 1990;247:1465-8.

55. Conry RM, LoBuglio AF, Wright M, Sumerel L, Pike MJ, Johanning F, et al. Characterization of a messenger RNA polynucleotide vaccine vector. Cancer Res. 1995;55:1397-400.

56. Carralot JP, Probst J, Hoerr I, Scheel B, Teufel R, Jung G, et al. Polarization of immunity induced by direct injection of naked sequence-stabilized mRNA vaccines. Cell Mol Life Sci. 2004;61:2418-24.

57. Qiu P, Ziegelhoffer P, Sun J, Yang NS. Gene gun delivery of mRNA in situ results in efficient transgene expression and genetic immunization. Gene Ther. 1996;3:262-8.

58. Steitz J, Britten CM, Wolfel T, Tuting T. Effective induction of anti-melanoma immunity following genetic vaccination with synthetic mRNA coding for the fusion protein EGFP.TRP2. Cancer Immunol Immunother. 2006;55:246-53.

59. Kreiter S, Selmi A, Diken M, Koslowski M, Britten CM, Huber C, et al. Intranodal vaccination with naked antigen-encoding RNA elicits potent prophylactic and therapeutic antitumoral immunity. Cancer Res. 2010;70:9031-40

60. Kreiter S, Diken M, Selmi A, Diekmann J, Attig S, Husemann Y, et al. FLT3 ligand enhances the cancer therapeutic potency of naked RNA vaccines. Cancer Res. 2011;71:6132-42.

61. Weide B, Carralot JP, Reese A, Scheel B, Eigentler TK, Hoerr I, et al. Results of the first phase $1 /$ II clinical vaccination trial with direct injection of mRNA. J Immunother. 2008;31:180-8.

62. Rittig SM, Haentschel M, Weimer K, Heine A, Muller MR, Brugger W, et al. Intradermal vaccinations with RNA coding for TAA generate CD8+ and CD4+ immune responses and induce clinical benefit in vaccinated patients. Mol Therapy. 2011;19:990-9.

63. Carralot JP, Weide B, Schoor O, Probst J, Scheel B, Teufel R, et al. Production and characterization of amplified tumor-derived cRNA libraries to be used as vaccines against metastatic melanomas. Genetic Vaccines Therapy. 2005;3:6.

64. Ying $H$, Zaks TZ, Wang RF, Irvine KR, Kammula US, Marincola FM, et al. Cancer therapy using a self-replicating RNA vaccine. Nat Med. 1999;5:823-7.

65. Geall AJ, Verma A, Otten GR, Shaw CA, Hekele A, Banerjee K, et al. Nonviral delivery of self-amplifying RNA vaccines. Proc Natl Acad Sci U S A. 2012;109:14604-9.

66. Rodriguez-Gascon A, del Pozo-Rodriguez A, Solinis MA. Development of nucleic acid vaccines: use of self-amplifying RNA in lipid nanoparticles. Int J Nanomedicine. 2014;9:1833-43.

67. Jackson CA, Messinger J, Palmer MT, Peduzzi JD, Morrow CD. Gene expression in the muscle and central nervous system following 
intramuscular inoculation of encapsidated or naked poliovirus replicons. Virology. 2003;314:45-61.

68. Vignuzzi M, Gerbaud S, van der Werf S, Escriou N. Naked RNA immunization with replicons derived from poliovirus and Semliki Forest virus genomes for the generation of a cytotoxic T cell response against the influenza A virus nucleoprotein. J Gen Virol. 2001;82:1737-47.

69. Kofler RM, Aberle JH, Aberle SW, Allison SL, Heinz FX, Mandl CW. Mimicking live flavivirus immunization with a noninfectious RNA vaccine. Proc Natl Acad Sci U S A. 2004;101:1951-6.

70. Morse MA, Hobeika AC, Osada T, Berglund P, Hubby B, Negri S, et al. An alphavirus vector overcomes the presence of neutralizing antibodies and elevated numbers of Tregs to induce immune responses in humans with advanced cancer. J Clin Invest. 2010;120:3234-41.

71. Scheel B, Aulwurm S, Probst J, Stitz L, Hoerr I, Rammensee HG, et al. Therapeutic anti-tumor immunity triggered by injections of immunostimulating single-stranded RNA. Eur J Immunol. 2006:36:2807-16.

72. Kallen KJ, Heidenreich R, Schnee M, Petsch B, Schlake T, Thess A, et al. A novel, disruptive vaccination technology: self-adjuvanted RNActive((R)) vaccines. Human Vaccines Immunotherapeut. 2013;9:2263-76.

73. Scheel B, Braedel S, Probst J, Carralot JP, Wagner H, Schild H, et al. Immunostimulating capacities of stabilized RNA molecules. Eur J Immunol. 2004;34:537-47.

74. Fotin-Mleczek M, Zanzinger K, Heidenreich R, Lorenz C, Thess A, Duchardt $\mathrm{KM}$, et al. Highly potent mRNA based cancer vaccines represent an attractive platform for combination therapies supporting an improved therapeutic effect. J Gene Med. 2012;14:428-39.

75. Weide B, Pascolo S, Scheel B, Derhovanessian E, Pflugfelder A, Eigentler TK, et al. Direct injection of protamine-protected mRNA: results of a phase 1/2 vaccination trial in metastatic melanoma patients. J Immunother. 2009;32:498-507.

76. Heidenreich R, Jasny E, Kowalczyk A, Lutz J, Probst J, Baumhof P, Scheel B, Voss S, Kallen K, Fotin-Mleczek M: A novel RNA-based adjuvant combines strong immunostimulatory capacities with a favorable safety profile. Int Cancer 2014; doi: 10.1002/ijc.29402

77. Rausch S, Schwentner C, Stenzl A, Bedke J: mRNA vaccine CV9103 and CV9104 for the treatment of prostate cancer. Human Vaccines Immunotherapeut 2014;10:3146-52.

78. Sebastian M, Papachristofilou A, Weiss C, Fruh M, Cathomas R, Hilbe W, et al Phase Ib study evaluating a self-adjuvanted mRNA cancer vaccine (RNActive (R)) combined with local radiation as consolidation and maintenance treatment for patients with stage IV non-small cell lung cancer. BMC Cancer. 2014;14:748

79. Martinon F, Krishnan S, Lenzen G, Magne R, Gomard E, Guillet JG, et al. Induction of virus-specific cytotoxic T lymphocytes in vivo by liposome-entrapped mRNA. Eur J Immunol. 1993;23:1719-22.

80. Joshi MD, Unger WJ, Storm G, van Kooyk Y, Mastrobattista E. Targeting tumor antigens to dendritic cells using particulate carriers. J Control Release. 2012;161:25-37.

81. Markov OO, Mironova NL, Maslov MA, Petukhov IA, Morozova NG, Vlassov W, et al. Novel cationic liposomes provide highly efficient delivery of DNA and RNA into dendritic cell progenitors and their immature offsets. J Controlled Release. 2012;160:200-10.

82. Nair S, Zhou F, Reddy R, Huang L, Rouse BT. Soluble proteins delivered to dendritic cells via $\mathrm{pH}$-sensitive liposomes induce primary cytotoxic $\mathrm{T}$ lymphocyte responses in vitro. J Experimen Med. 1992;175:609-12.

83. Chikh G, Schutze-Redelmeier MP. Liposomal delivery of CTL epitopes to dendritic cells. Biosci Rep. 2002;22:339-53.

84. Hess PR, Boczkowski D, Nair SK, Snyder D, Gilboa E. Vaccination with mRNAs encoding tumor-associated antigens and granulocyte-macrophage colony-stimulating factor efficiently primes CTL responses, but is insufficient to overcome tolerance to a model tumor/self antigen. Cancer Immunol Immunother. 2006;55:672-83.

85. Mockey M, Bourseau E, Chandrashekhar V, Chaudhuri A, Lafosse S, Le Cam E, et al. mRNA-based cancer vaccine: prevention of B16 melanoma progression and metastasis by systemic injection of MART1 mRNA histidylated lipopolyplexes. Cancer Gene Ther. 2007;14:802-14.

86. Ransohoff RM, Kivisakk P, Kidd G. Three or more routes for leukocyte migration into the central nervous system. Nat Rev Immunol. 2003; 3:569-81.

87. Bungener L, Serre K, Bijl L, Leserman L, Wilschut J, Daemen T, et al. Virosome-mediated delivery of protein antigens to dendritic cells. Vaccine. 2002;20:2287-95.
88. Serre K, Machy P, Grivel JC, Jolly G, Brun N, Barbet J, et al. Efficient presentation of multivalent antigens targeted to various cell surface molecules of dendritic cells and surface lg of antigen-specific B cells. J Immunol. 1998;161:6059-67.

89. Copland MJ, Baird MA, Rades T, McKenzie JL, Becker B, Reck F, et al. Liposomal delivery of antigen to human dendritic cells. Vaccine. 2003;21:883-90.

90. van Broekhoven CL, Parish CR, Demangel C, Britton WJ, Altin JG. Targeting dendritic cells with antigen-containing liposomes: a highly effective procedure for induction of antitumor immunity and for tumor immunotherapy. Cancer Res. 2004:64:4357-65.

91. Edlich B, Hogdal LJ, Rehermann B, Behrens SE. Dendritic cells transfected with Her2 antigen-encoding RNA replicons cross-prime CD8 T cells and protect mice against tumor challenge. Vaccine. 2010;28:7764-73.

92. Ponsaerts P, Van Tendeloo VF, Berneman ZN. Cancer immunotherapy using RNA-loaded dendritic cells. Clin Exp Immunol. 2003;134:378-84.

93. Heiser A, Maurice MA, Yancey DR, Coleman DM, Dahm P, Vieweg J. Human dendritic cells transfected with renal tumor RNA stimulate polyclonal T-cell responses against antigens expressed by primary and metastatic tumors. Cancer Res. 2001;61:3388-93.

94. Aytekin C, Germeshausen M, Tuygun N, Tanir G, Dogu F, Ikinciogullari A. Kostmann disease with developmental delay in three patients. Eur J Pediatr. 2010;169:759-62

95. Wilgenhof S, Van Nuffel AM, Benteyn D, Corthals J, Aerts C, Heirman C, et al. A phase IB study on intravenous synthetic mRNA electroporated dendritic cell immunotherapy in pretreated advanced melanoma patients. Ann Oncol. 2013;24:2686-93.

96. Benteyn D, Van Nuffel AM, Wilgenhof S, Corthals J, Heirman C, Neyns B, et al. Characterization of CD8+ T-cell responses in the peripheral blood and skin injection sites of melanoma patients treated with mRNA electroporated autologous dendritic cells (TriMixDC-MEL). BioMed Res Int. 2013;2013:976383.

97. Farrell D, Ptak K, Panaro NJ, Grodzinski P. Nanotechnology-based cancer therapeutics-promise and challenge-lessons learned through the $\mathrm{NCl}$ Alliance for Nanotechnology in Cancer. Pharm Res. 2011;28:273-8.

98. Ferrari M. Cancer nanotechnology: opportunities and challenges. Nat Rev Cancer. 2005;5:161-71.

99. Heath JR, Davis ME. Nanotechnology and cancer. Annu Rev Med. 2008:59:251-65.

100. Peer D, Karp JM, Hong S, Farokhzad OC, Margalit R, Langer R. Nanocarriers as an emerging platform for cancer therapy. Nat Nanotechnol. 2007:2:751-60.

101. Zhang L, Gu FX, Chan JM, Wang AZ, Langer RS, Farokhzad OC. Nanoparticles in medicine: therapeutic applications and developments. Clin Pharmacol Ther. 2008;83:761-9.

102. Nguyen DN, Mahon KP, Chikh G, Kim P, Chung H, Vicari AP, et al. Lipid-derived nanoparticles for immunostimulatory RNA adjuvant delivery. Proc Natl Acad Sci U S A. 2012;109:E797-803.

103. Nembrini C, Stano A, Dane KY, Ballester M, van der Vlies AJ, Marsland BJ, et al. Nanoparticle conjugation of antigen enhances cytotoxic T-cell responses in pulmonary vaccination. Proc Natl Acad Sci U S A. 2011;108:E989-97.

104. Perche F, Benvegnu T, Berchel M, Lebegue L, Pichon C, Jaffres PA, et al. Enhancement of dendritic cells transfection in vivo and of vaccination against B16F10 melanoma with mannosylated histidylated lipopolyplexes loaded with tumor antigen messenger RNA. Nanomedicine. 2011;7:445-53.

105. Harries M, Ellis P, Harper P. Nanoparticle albumin-bound paclitaxel for metastatic breast cancer. J Clinical Oncol. 2005;23:7768-71.

106. Choi J, Wang NS. Nanoparticles in Biomedical Applications and Their Safety Concerns. In: Fazel R, editor. Biomedical Engineering- From Theory to Applications. InTech. 2011; DOI: 10.5772/18452.

107. McNeil SE. Nanoparticle therapeutics: a personal perspective. Wiley Interdiscip Rev Nanomed Nanobiotechnol. 2009;1:264-71.

108. Adiseshaiah PP, Hall JB, McNeil SE. Nanomaterial standards for efficacy and toxicity assessment. Wiley Interdiscip Rev Nanomed Nanobiotechnol. 2010;2:99-112

109. Bawa R. Nanoparticle-based Therapeutics in Humans: A survey. Nanotechnology Law Business. 2008;5:135-55.

110. Fasol U, Frost A, Buchert M, Arends J, Fiedler U, Scharr D, et al. Vascular and pharmacokinetic effects of EndoTAG-1 in patients with advanced cancer and liver metastasis. Ann Oncol. 2012;23:1030-6. 